\title{
CARACTERÍSTICAS DA COMBUSTÃO DE UM MOTOR DIESEL COM INJEÇÃO DIRETA DE MISTURAS DE ÓLEO DIESEL E ETANOL E INJEÇÃO INDIRETA DE ETANOL
}

\author{
Alex de Oliveira ${ }^{1}$ \\ José Ricardo Sodré ${ }^{1}$ \\ ${ }^{1}$ Pontifícia Universidade Católica de Minas Gerais - Departamento de Engenharia \\ Mecânica
}

E-mails: alexoem@gmail.com, ricardo@pucminas.br

\begin{abstract}
RESUMO
Pesquisas sobre a aplicação de combustíveis renováveis alternativos em motores Diesel têm ganho interesse. A estratégia de operação bicombustível, usando etanol e óleo diesel como combustíveis, é atraente devido ao potencial de reduzir as emissões regulamentadas, como óxidos de nitrogênio $\left(\mathrm{NO}_{\mathrm{X}}\right)$ e material particulado (MP), e aumentar a eficiência de conversão do combustível. Para compreender claramente os efeitos da utilização da técnica bicombustível em motores diesel, existe a necessidade de estudar os parâmetros de combustão. A presente investigação avaliou os efeitos da utilização de etanol por duas técnicas distintas, injeção direta de misturas de óleo diesel e etanol e injeção indireta de etanol com injeção direta de óleo diesel. Foram avaliados a taxa de aumento de pressão no cilindro, o atraso da ignição e a taxa líquida de liberação de calor para determinar a duração da combustão e o ângulo do virabrequim em que há liberação de 50\% do calor total (CA50). Altas taxas de aumento de pressão podem causar detonação no cilindro e o parâmetro CA50 é importante, pois traduz a eficiência de conversão de energia do combustível no motor. Os testes foram realizados em um motor diesel de quatro cilindros, $44 \mathrm{~kW}$, alimentado por misturas de óleo diesel e etanol com concentrações de até $15 \%$ de etanol e injeção indireta de até $30 \%$ de etanol. Os resultados mostraram que a adição do etanol causou um aumento no atraso de ignição, na taxa de acréscimo da pressão no cilindro e na duração de combustão reduzida, com aumento da quantidade de calor liberado durante a fase pré-misturada da combustão. Não foram observados danos ao motor com a adição de etanol.
\end{abstract}

\section{INTRODUÇÃO}

Os combustíveis fósseis estão presentes em inúmeras áreas da economia e foram fundamentais para o crescimento e modernização da civilização, tornando-se indispensáveis para diversos setores como indústria, transporte, geração de energia, agricultura, dentre outros [1]. Nos últimos anos, houve um grande aumento das fiscalizações das emissões de motores de combustão interna e crescente preocupação com o meio ambiente. Os motores diesel são um dos motores térmicos mais utilizados no setor de transporte, se destacando pela alta eficiência de conversão de energia, alto torque e confiabilidade, em relação aos motores com ignição por centelha [2]. Apesar da maior eficiência, os motores diesel emitem maiores níveis de óxidos de nitrogênio $\left(\mathrm{NO}_{\mathrm{X}}\right)$ e material particulado (MP). Pesquisas para aumentar a eficiência de conversão do combustível e reduzir os níveis de emissões são 
realizadas por modificações construtivas, controle da formação da mistura ou modificação dos combustíveis [3]. A emissão de $\mathrm{NO}_{X}$ e MP é um dos maiores problemas de poluição das grandes cidades, tornando a busca por combustíveis menos poluentes cada vez mais intensa [4-7].

Um dos combustíveis mais promissores para substituir os combustíveis derivados do petróleo são os álcoois, principalmente etanol e metanol. O etanol é um combustível alternativo atrativo por ser um combustível oxigenado de fonte renovável, livre de enxofre, possuir alto calor latente de vaporização e alta velocidade de queima, com elevado potencial de redução de $\mathrm{NO}_{\mathrm{X}}$ e MP em motores com ignição por compressão [8-11]. As limitações do uso de etanol em motores diesel envolvem a redução das propriedades lubrificantes e da capacidade de ignição do combustível, baixa miscibilidade e menor poder calorífico em relação ao óleo diesel [10,12-15]. Os motores diesel têm a particularidade de poderem ser configurados para operação bicombustível [16]. Existem diversas técnicas para o uso de etanol em motores diesel [17]. Mistura de combustíveis, injeção de álcool no coletor de admissão, injeção direta de álcool e óleo diesel na câmara de combustão e instalação de sistema de ignição por centelha estão entres estes métodos.

A injeção de etanol no coletor de admissão permite altos percentuais de substituição. Esse método requer todo o sistema de controle da injeção de etanol, como injetores, bomba, tanque e central eletrônica [17]. A injeção do álcool no coletor de admissão de motores diesel possibilita a substituição de mais de $50 \%$ de óleo diesel. A injeção direta de álcool e óleo diesel na câmara de combustão, em sistemas de injeção separados, possibilita a substituição de até $90 \%$ do óleo diesel. Já a mistura dos dois combustíveis possibilita até $25 \%$ de substituição da demanda de óleo diesel, limitada pela baixa miscibilidade do etanol no óleo diesel, que causa a separação de fases $(9,15,17-20)$.

Os efeitos da adição de etanol são dependentes das características construtivas do motor, modo de operação e percentual de substituição. Diversos estudos indicam redução das emissões de $\mathrm{NO}_{\mathrm{x}}$ e fuligem com a utilização de misturas de óleo diesel e etanol $[10,13,18$, 20-27], mas com possibilidade de aumento, principalmente com o aumento da pressão no interior do cilindro [25,27-30] A adição de etanol pode aumentar as emissões de hidrocarbonetos não queimados e CO [10,13,18,21-26,30]. A eficiência de conversão de energia do combustível também é dependente das condições de operação, havendo relatos de redução ou aumento com a adição de etanol [10,13,21,25].

Mohammadi et al. [28] mostraram um rápido aumento da pressão no interior do cilindro em cargas altas e combustão incompleta e instável em cargas baixas com o uso de etanol em um motor diesel. Este efeito foi reduzido com alterações no sistema de injeção. Os autores concluem que, para utilização de concentrações de etanol acima de $20 \%$, o sistema de injeção de combustível deve ser alterado para possibilitar um funcionamento estável do motor.

Zhu et al. [31] realizaram experimentos com um motor diesel naturalmente aspirado alimentado por misturas de biodiesel e etanol anidro. Os autores relatam aumento do pico de pressão no interior do cilindro e da taxa de liberação de calor com o aumento da concentração de etanol utilizada, além de maior atraso na ocorrência do pico de pressão na combustão, em comparação com o uso de biodiesel puro. Esse atraso ocorre devido ao menor número de cetano da mistura e ao efeito de diminuição da temperatura da mistura ar/combustível devido ao alto calor latente de vaporização do etanol, que também resulta em maior quantidade de combustível queimado na fase pré-misturada da combustão. Houve diminuição da duração 
da combustão com o uso de etanol, em comparação com biodiesel puro, explicado pelo maior conteúdo de oxigênio da mistura biodiesel e etanol, que aumenta a oxidação durante a queima e reduz o tempo de combustão. Uma combustão mais rápida pode aumentar a eficiência térmica do motor, o que ocorreu para a mistura com $5 \%$ de etanol.

Hulwan e Joshi [13] também relatam aumentos no atraso da ignição com o uso de misturas de óleo diesel. Os autores destacam que o etanol diminui a viscosidade da mistura em relação ao óleo diesel puro, o que melhora a distribuição da mistura ar/combustível e aumenta o percentual de combustível queimado na fase pré-misturada da combustão. A magnitude do pico de pressão no cilindro, de uma forma geral, diminuiu com o aumento da concentração de etanol na mistura, para o ângulo de injeção original do motor. Os autores relataram um pequeno aumento da eficiência térmica para cargas altas, em relação ao motor com óleo diesel puro. Esse aumento foi justificado pela rápida fase pré-misturada da combustão causada pela melhor mistura ar/combustível durante o atraso na ignição, pelo aumento de oxigênio na mistura e pela combustão pobre.

Para Zhu et al. [21] o oxigênio no etanol pode melhorar o processo de combustão com maior taxa de calor queimado nas fases pré-misturada e difusiva, suprimindo a formação de MP e acelerando a oxidação deste material durante a exaustão. No trabalho de Fang et al. [23] a adição de etanol aumentou o pico de pressão no interior do cilindro e o atraso de ignição, indicando maior quantidade de combustível queimada na fase de combustão pré-misturada. As maiores taxas de calor liberado na combustão foram encontradas para a maior concentração de etanol.

Oliveira et al. [32] avaliaram o desempenho e emissões do motor apresentado no presente trabalho operando com misturas de óleo diesel e etanol. A adição de etanol aumentou o consumo específico do motor em até $8,5 \%$, devido ao menor poder calorífico desse combustível. Com relação às emissões, houve redução das emissões de $\mathrm{CO}_{2}$ com o aumento do percentual de etanol, chegando a uma redução de 8,6\%. As emissões de $\mathrm{CO}$ aumentaram para cargas baixas, principalmente na operação com $15 \%$ de etanol, chegando a um aumento de $38,7 \%$, e foram reduzidas em cargas altas, principalmente na operação com $10 \%$ de etanol, chegando a uma redução de $22,7 \%$. As emissões de hidrocarbonetos não-queimados apresentaram comportamento semelhante, com aumento máximo de $19,1 \%$ com o uso de $10 \%$ de etanol em cargas baixas e redução máxima de $28 \%$ com o uso de $15 \%$ de etanol em cargas altas. A adição do etanol reduziu as emissões de $\mathrm{NO}$, principalmente em cargas altas, atingindo uma redução de até $10,4 \%$.

A adição de combustíveis complementares ao ar admitido por motores de combustão interna, chamada de injeção indireta, vem sendo investigada desde o final da década de 1920, com a comercialização do primeiro veículo bicombustível em 1939 [33]. Este é um método que requer poucas modificações no motor, sendo o álcool injetado no coletor de admissão através de injetores de baixa pressão. A injeção do etanol tende a diminuir a fuligem gerada pelo motor [36]. Rezende et al. [35] mostrou a viabilidade da implementação de um controle integrado de injeção de óleo diesel diretamente na câmara de combustão e de etanol no coletor de ar de um motor diesel de um caminhão de $265 \mathrm{~kW}$ de potência.

Tsang et al. [12] investigaram um motor diesel utilizando a técnica de injeção de etanol no coletor de admissão. Através de dados de pressão no interior do cilindro, os autores calcularam a taxa de liberação de calor e mostraram o mesmo padrão na combustão do óleo diesel puro e na combustão do óleo diesel e do etanol. Com base nesses dados foi percebido 
que, com a atomização do etanol, uma parte do óleo diesel que antes era queimado na fase difusiva da combustão passou a ser queimada na fase pré-misturada. Na menor carga ensaiada o pico de pressão no interior do cilindro foi reduzido com o aumento do percentual de etanol atomizado, mas, para cargas maiores, essa pressão aumenta com o aumento da quantidade de etanol. Já o pico da taxa de liberação de calor cresceu com o aumento da utilização de etanol em todas as cargas ensaiadas. Os autores explicam que, na menor carga utilizada, a mistura de etanol e ar é muito pobre, o que levou a baixas taxas de combustão e pouca influência nas características da combustão.

Sarjovaara, Alantie e Larmi [36] utilizaram a técnica de injeção de etanol no coletor de admissão de um motor diesel e relatam que, quando mantidos os parâmetros de injeção de óleo diesel nas condições originais, a combustão no modo bicombustível se mostrou mais rápida e intensa, com aumento dos picos de pressão e podendo ocorrer o fenômeno da detonação, principalmente em cargas altas. A taxa de liberação de calor mostrou-se intensa na fase pré-misturada da combustão com o uso de etanol, mas um pouco menor em comparação com o uso de óleo diesel puro. Os autores concluem que, para conseguir maiores percentuais de substituição, é necessário alterar a estratégia de injeção de óleo diesel, como dividir a quantidade de óleo diesel fornecida por ciclo em duas ou mais injeções.

Tutak [34] mostrou que a adição de etanol no ar admitido reduz a pressão durante o curso de admissão, devido ao efeito de resfriamento causado pelo combustível, e causa aumento do pico de pressão durante a combustão em carga plena. Com o aumento do percentual de etanol houve o aumento do atraso de ignição e aumento do pico da taxa de liberação de calor, justificado pelo maior atraso de ignição do óleo diesel. Com o uso de $90 \%$ de etanol houve um grande atraso de ignição, com a combustão ocorrendo durante um curso avançado de expansão do cilindro (misfiring). Hansdah e Murugan [37] explicam que o etanol é um combustível com cerca de $35 \%$ de oxigênio e, quanto maior a quantidade de combustível oxigenado acumulado durante o atraso da ignição, maior a quantidade de oxigênio para o óleo diesel se queimar, resultado em rápido aumento da pressão no interior do cilindro.

Sarjovaara e Larmi [38] utilizaram etanol injetado no coletor de admissão de um motor diesel de seis cilindros e $120 \mathrm{~kW}$ de potência. Os autores investigaram o percentual máximo de substituição do óleo diesel pelo E85 e chegaram a 89\% em cargas médias, limitado pela taxa de aumento da pressão no interior do cilindro. Jamuwa et al. [39] estudaram o desempenho de um motor diesel estacionário operando com injeção indireta de etanol. Os resultados mostraram aumento do pico de pressão no cilindro, da taxa de aumento da pressão e do atraso de ignição, e redução da duração da combustão.

O presente estudo tem o objetivo de avaliar as características de combustão de um motor diesel operando com duas técnicas de alimentação de etanol: injeção direta de misturas de óleo diesel e etanol e injeção indireta de etanol com injeção direta de óleo diesel como combustível piloto. Foram avaliados os níveis de pressão no interior do cilindro, taxa de aumento da pressão e características da combustão, como taxa líquida de liberação de calor, atraso de ignição e duração da combustão.

\section{METODOLOGIA EXPERIMENTAL}

Os experimentos foram desenvolvidos em um motor com as características mostradas pela Tabela 1. 
Tabela 1 - Características do motor diesel MWM

\begin{tabular}{ll}
\hline PARÂMETRO & TIPO OU VALOR \\
\hline Fabricante/Modelo & MWM D229-4 \\
Potência máxima @ $1500 \mathrm{rpm}$ & $40 \mathrm{~kW}$ \\
Potência máxima @ $1800 \mathrm{rpm}$ & $49 \mathrm{~kW}$ \\
Tipo de construção & Diesel - 4 tempos em linha \\
Tipo de injeção & Direta \\
Ordem de ignição & $1-3-4-2$ \\
Diâmetro x curso & $102 \times 120 \mathrm{~mm}$ \\
Comprimento da biela & 207 mm \\
Cilindrada unitária & 0,980 litros \\
Número de cilindros & 4 \\
Cilindrada total & 3,922 litros \\
Aspiração & Natural \\
Razão de compressão & $17: 1$ \\
Momento de início da injeção & $23^{\circ} \mathrm{CA}$ APMS \\
Ângulo de abertura da válvula de exaustão & $510^{\circ} \mathrm{CA}$ DPMS \\
Ângulo de fechamento da válvula de admissão & $210^{\circ} \mathrm{CA}$ DPMS \\
Ângulo de abertura da válvula de admissão & $0^{\circ} \mathrm{CA}$ DPMS \\
Ângulo de fechamento da válvula de exaustão & $720^{\circ} \mathrm{CA}$ DPMS \\
\hline & \\
\hline
\end{tabular}

O óleo diesel foi substituído parcialmente por etanol. Esta substituição se deu através de duas metodologias distintas: injeção direta de misturas de etanol anidro e óleo diesel e injeção indireta de etanol hidratado com injeção direta de óleo diesel. Com base na literatura e visando evitar danos ao motor, a Tabela 2 mostra as proporções de etanol que foram utilizadas e a nomenclatura utilizada para apresentação dos resultados. O termo B7 equivale ao óleo diesel comercial contendo 7\% de biodiesel, de acordo com a Lei ANP N ${ }^{\circ} 13.033$ de 24.09.2014. As concentrações das misturas apresentadas foram determinadas em base mássica e o cálculo da massa de etanol que deve ser injetada por ciclo foi obtido a partir da energia que deve ser fornecida para substituir o percentual requerido de óleo diesel:

$$
\dot{m}_{e}=P_{\%} \frac{\dot{m}_{d_{0}} P C I_{d}}{P C I_{e}}
$$

onde:

$P_{\%}=$ percentual de substituição $(\%)$

$\dot{m}_{e}=$ vazão mássica de etanol $(\mathrm{kg} / \mathrm{h})$

$\dot{m}_{d_{0}}=$ consumo de óleo diesel no modo padrão $(\mathrm{kg} / \mathrm{h})$

$P C I_{d}=$ poder calorífico inferior do óleo diesel $(\mathrm{MJ} / \mathrm{kg})$

$P C I_{e}=$ poder calorífico inferior do etanol $(\mathrm{MJ} / \mathrm{kg})$ 
Tabela 2 - Modos de operação utilizando óleo diesel e etanol

\begin{tabular}{cccc}
\hline $\begin{array}{c}\text { Misturas etanol/óleo } \\
\text { diesel }\end{array}$ & Nomenclatura & $\begin{array}{c}\text { Injeção indireta de } \\
\text { etanol }\end{array}$ & Nomenclatura \\
\hline $0 \%$ & B7E0 & $0 \%$ & B7E0 \\
$5 \%$ & B7E5 & $5 \%$ & IB7E5 \\
$10 \%$ & B7E10 & $10 \%$ & IB7E10 \\
$15 \%$ & B7E15 & $15 \%$ & IB7E15 \\
- & - & $20 \%$ & IB7E25 \\
- & - & $30 \%$ & IB7E30 \\
\hline
\end{tabular}

O sistema de injeção de óleo diesel do motor é controlado mecanicamente e possui um acelerador com a função de manter a rotação do motor constante a $1800 \mathrm{rpm}$. Ao enriquecer a mistura ar/combustível com a adição de etanol, o acelerador eletrônico atua e corrige a vazão de óleo diesel, mantendo a rotação constante e possibilitando a utilização do motor no modo bicombustível. Injetores utilizados no meio automotivo foram instalados no coletor de admissão de ar no motor e um sistema de controle eletrônico dos injetores foi desenvolvido de modo a fornecer o etanol na quantidade requerida e nos tempos adequados. Um sistema de aquisição de dados foi utilizado para avaliar o desempenho do motor operando nas condições pesquisadas. O sistema é constituído de sensores, transdutores, circuitos condicionadores de sinais, duas placas de aquisição de dados e um programa na plataforma LabVIEW. Os principais parâmetros adquiridos por esse sistema são mostrados na Fig. 1.

Figura 1 - Diagrama do aparato experimental

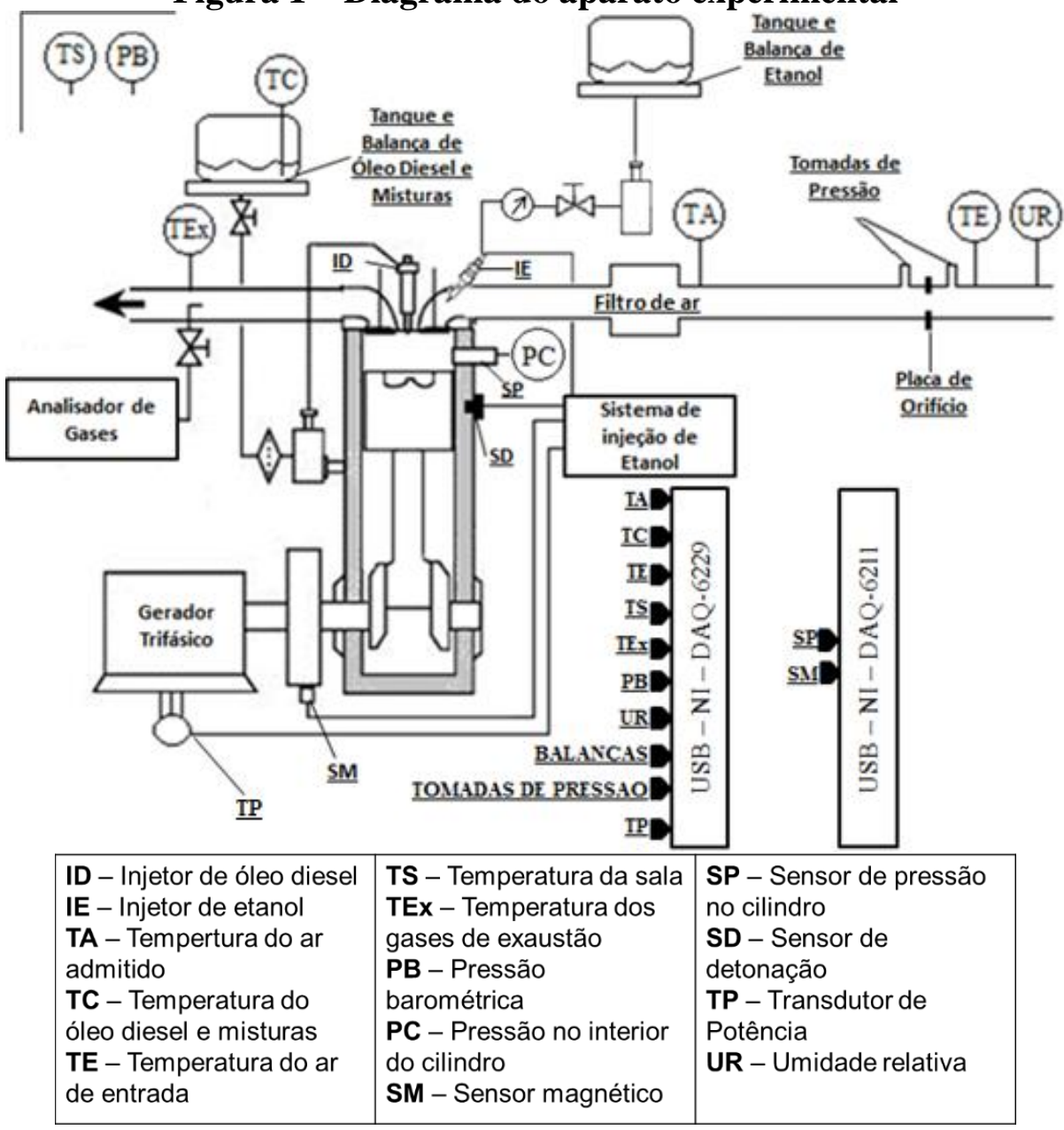


A pressão no interior do primeiro cilindro do motor foi medida através de um sensor piezoelétrico de quartzo modelo $6061 \mathrm{~B}$ com resolução de $\pm 0,5 \%$, fabricado pela Kistler Instrument Corporation. Para a conversão da variação de carga elétrica proveniente do sensor para uma variação linear de tensão, foi utilizado o amplificador de Carga 5037B3. A taxa de aquisição dos dados foi configurada em $100 \mathrm{kHz}$. Com a operação na rotação constante de 1800 RPM e utilizando uma roda dentada posicionada no eixo do motor e um sensor magnético, obteve-se uma resolução angular de $0,108^{\circ} \mathrm{CA}$. Considerou-se o início da combustão como o máximo valor da derivada segunda da curva de pressão em relação ao ângulo do virabrequim, baseado em que a taxa de liberação de energia na forma de calor liberado é diretamente proporcional à taxa de variação da pressão na câmara de combustão [40]. A diferença entre o ângulo de início de injeção (23ㅅMS) e o ângulo determinado como de início da combustão foi considerado como o atraso de ignição [41].

Heywood [41] define a taxa de liberação de calor como a taxa com que a energia química do combustível é liberada pelo processo de combustão. Pode-se determinar esse parâmetro através da curva de pressão interna do cilindro de um motor em função do ângulo do virabrequim. Calcula-se a energia necessária para se obter a pressão medida experimentalmente. Determinou-se a taxa líquida aparente de liberação de calor por:

onde:

$$
\frac{d Q_{l}}{d \theta}=\left(\frac{\gamma}{\gamma-1}\right) \cdot p \cdot \frac{d V}{d \theta}+\frac{1}{\gamma-1} \cdot V \cdot \frac{d P}{d \theta}
$$

$d Q_{l} / d \theta$ - taxa aparente líquida de liberação de calor $\left(\mathrm{kJ} /{ }^{\circ} \mathrm{CA}\right)$;

$\mathrm{V}$ - volume no interior do cilindro $\left(\mathrm{m}^{3}\right)$;

$\mathrm{p}$ - pressão no interior do cilindro $(\mathrm{Pa})$;

$\mathrm{p} \mathrm{dV} / \mathrm{d} \theta$ - taxa do trabalho desenvolvido pelos gases sobre o pistão $\left(\mathrm{kJ} /{ }^{\circ} \mathrm{CA}\right)$;

$\gamma$ - razão entre os calores específicos $\left(c_{p} / c_{v}\right)$ (adimensional).

A partir da curva da taxa de liberação de calor foram determinados os parâmetros CA10, CA50 e CA90, que representam o ângulo do virabrequim onde ocorreu o acúmulo de 10, 50 e $90 \%$ do calor liberado acumulado, respectivamente. CA10 e CA50 podem também ser considerados como o início da combustão e o final da fase pré-misturada da combustão, respectivamente, e CA90 como o final da combustão $[39,42]$. Durante os ensaios, as cargas aplicadas ao motor foram variadas entre $0 \mathrm{~kW}$ e $37,5 \mathrm{~kW}$ e as leituras das grandezas mensuradas foram obtidas após o motor atingir o regime permanente, determinado pelas temperaturas de exaustão e do sistema de arrefecimento. Os testes foram realizados de acordo com a norma ISO 3046-1:2002.

\section{RESULTADOS E DISCUSSÃO}

A tendência das curvas de pressão e de taxa líquida de liberação de calor não foi alterada com adição do etanol. A taxa líquida de liberação de calor é composta por uma fase prémisturada, seguida da fase difusiva. Em geral, o aumento da concentração de etanol causou maior atraso de ignição e maior energia liberada na fase pré-misturada da combustão [23]. $\mathrm{O}$ etanol possui menor densidade e viscosidade em relação ao óleo diesel, propiciando melhor atomização do combustível e melhor formação da mistura ar/combustível [13]. Além disso, com o maior atraso de ignição, maior quantidade de combustível é queimada durante a fase pré-misturada. Esses fatores levam à queima rápida de maior quantidade de 
combustível e rápida liberação de calor, resultando em aumento do pico de pressão e da taxa de liberação de calor [31]. Os picos de pressão e de taxa de liberação de calor se mostraram dependentes das cargas e dos efeitos que a adição do etanol causa na combustão. A combinação de efeitos como redução do número de cetano, resfriamento devido ao alto calor latente de evaporação, atraso de ignição e ângulo da ignição causa diferentes comportamentos nas condições ensaiadas.

As Figs. 2 e 3 mostram as curvas de pressão no interior do cilindro e da taxa líquida de liberação de calor, respectivamente, para a carga de $10 \mathrm{~kW}$, para todos os combustíveis. Para todas as curvas o aumento da concentração de etanol causou maior deslocamento da curva para direita, se afastando do ponto morto superior do cilindro (PMS). Este comportamento é explicado pelo maior atraso de ignição das misturas com etanol, devido ao menor número de cetano dessas misturas, e ao efeito de resfriamento do etanol, como mostra a Fig. 4.

Para a carga de $10 \mathrm{~kW}$, o maior pico de pressão para as misturas ocorreu para o combustível B7E5 (31,2 bar), seguido do B7E10 (30,1 bar), B7E15 (29,7 bar) e B7E0 (29,6 bar) (Fig. 4). O maior pico de pressão na combustão do combustível B7E5 gerou, também, o maior pico de liberação de calor, junto com B7E15. Os picos da taxa de liberação de calor foram de $48,2 \mathrm{~J} /{ }^{\circ} \mathrm{CA}$ (B7E5), 48,2 J/ ${ }^{\circ} \mathrm{CA}$ (B7E15), 44,8 J/ ${ }^{\circ} \mathrm{CA}$ (B7E10) e 39,1 J/ ${ }^{\circ} \mathrm{CA}$ (B7E0). Nessa carga o menor atraso de ignição do combustível B7E5 em relação às outras misturas de etanol causou o início da combustão mais próximo do PMS e o maior pico de pressão. A quantidade de mistura ar/combustível formada pelas misturas com etanol durante a fase prémisturada foi suficiente para aumentar o pico de pressão em relação ao óleo diesel padrão [23]. Apesar de um pico de liberação de calor maior em relação ao B7E10, a combustão do B7E15 apresentou menor pico de pressão, justificado pelo maior atraso de ignição, $26,3^{\circ} \mathrm{CA}$, enquanto o B7E0 apresentou $24,6^{\circ} \mathrm{CA}$ de atraso.

Figura 2 - Pressão no interior do cilindro em função do combustível para carga de 10 kW

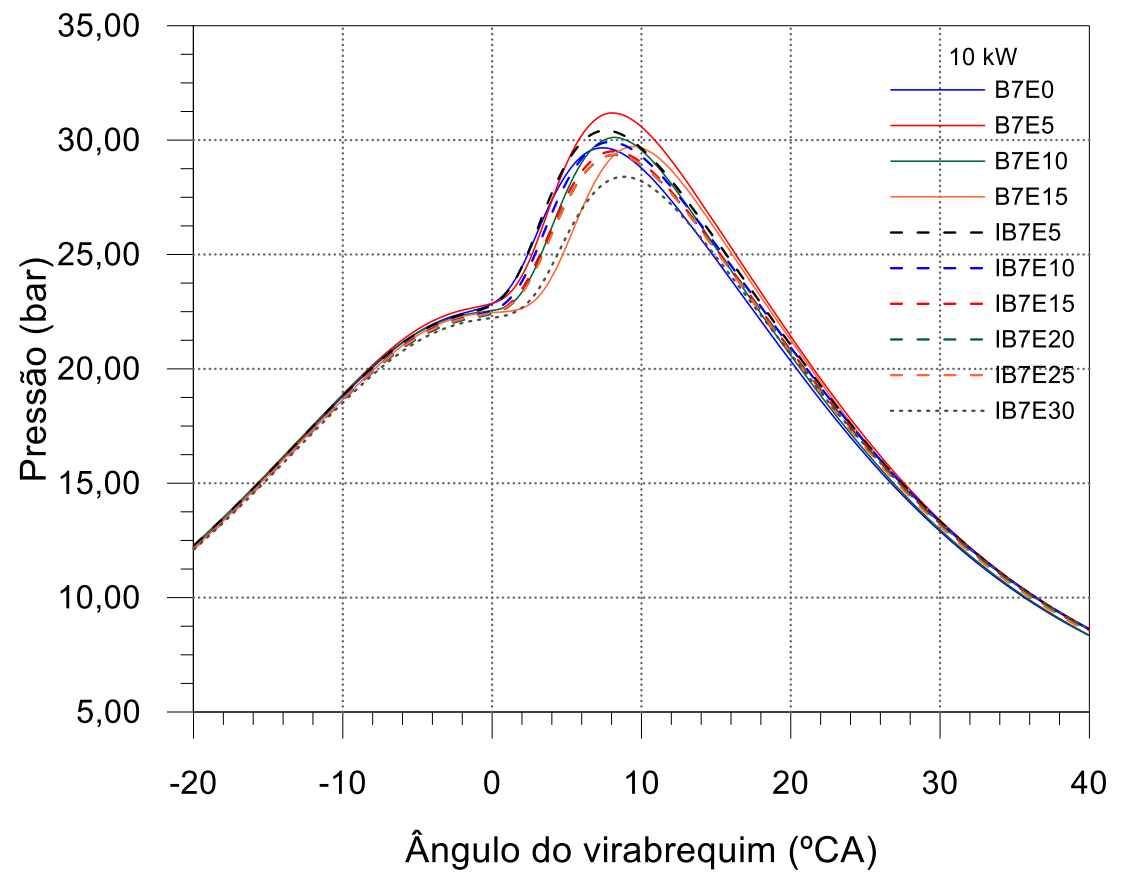


Figura 3 - Taxa líquida de liberação de calor em função do combustível para carga de $10 \mathrm{~kW}$

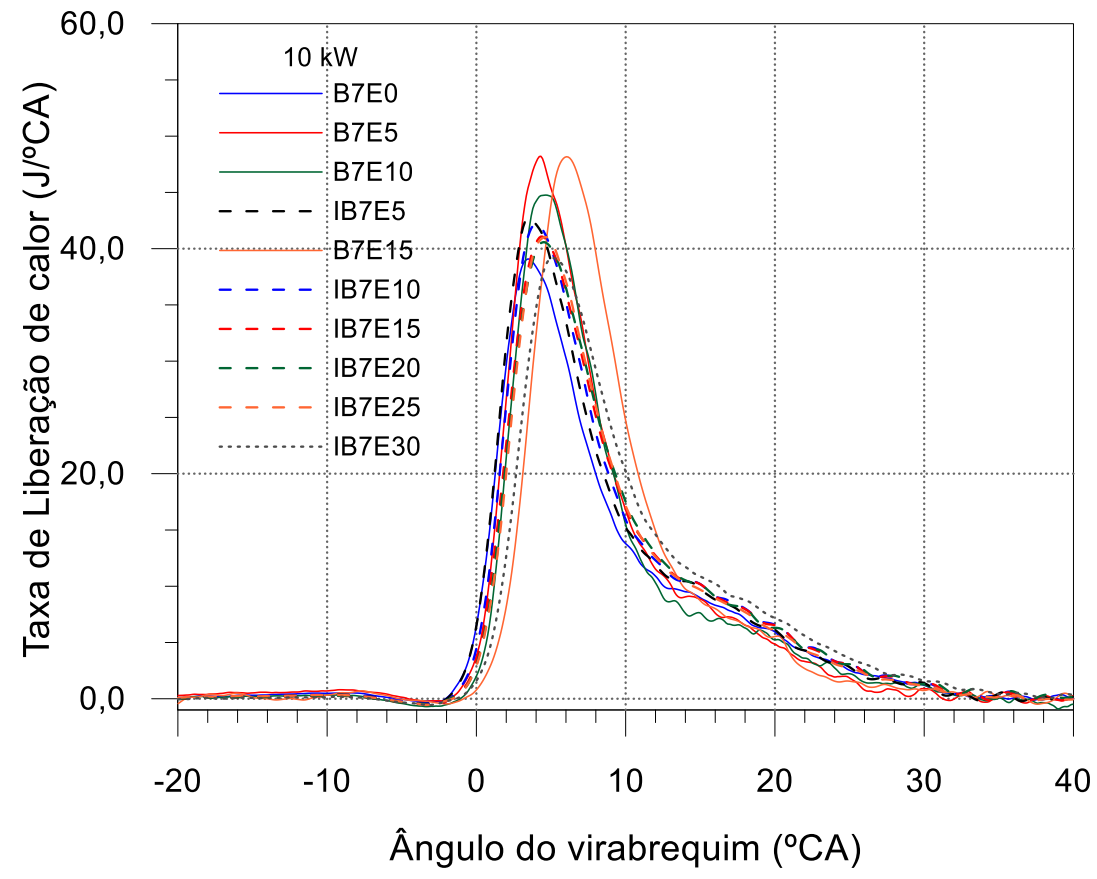

Figura 4 - Variação do atraso de ignição em função da carga e do combustível

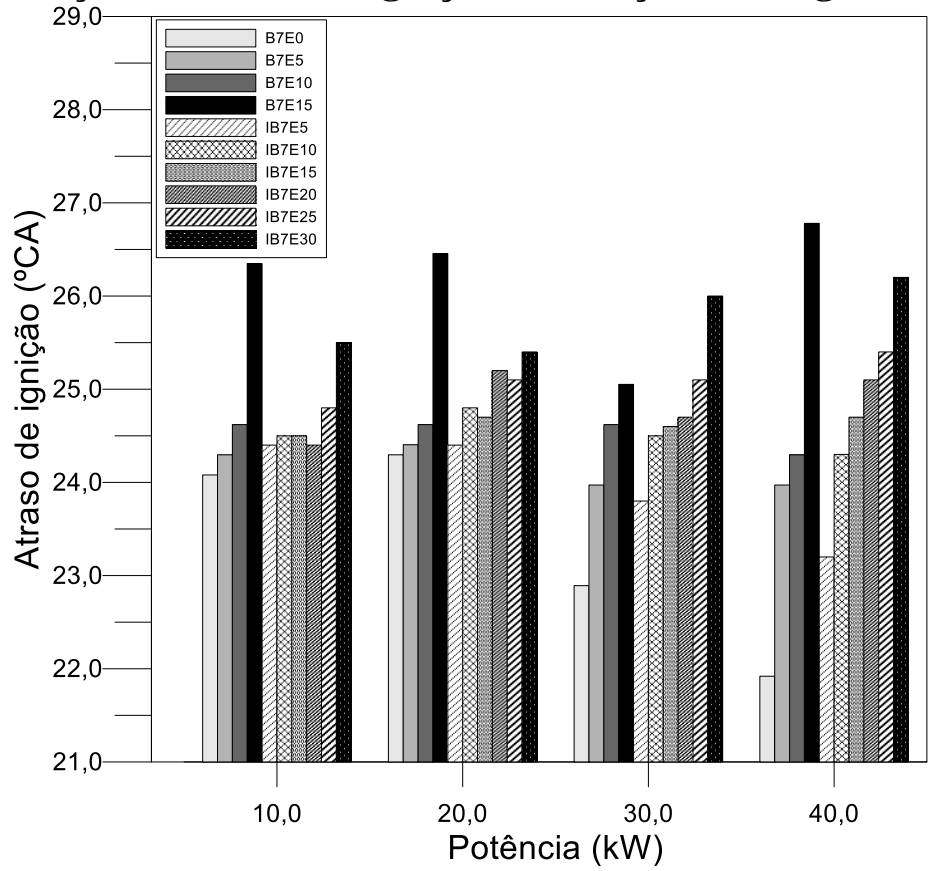

A injeção do etanol durante a admissão do ar causa redução da temperatura do gás no cilindro e aumenta o atraso de ignição [12]. A fase pré-misturada da mistura ar-óleo diesel-etanol é mais rica, queimando-se mais rapidamente. Assim, mais combustível é queimado na fase pré-misturada, causando aumento do pico de pressão no cilindro e do calor liberado para esse modo [7], o que foi observado nos experimentos em cargas altas (Figs. 2 e 3). Em cargas baixas, a baixa temperatura do gás no cilindro e o grande atraso na ignição resultam no pico de calor liberado deslocado em relação ao ponto morto superior (Fig. 3), causando diminuição do pico de pressão. Já em cargas altas, a temperatura do gás no cilindro é superior, o atraso na ignição é menor (Fig. 4) e a mistura ar-etanol é mais rica. 
O efeito de redução da temperatura do gás no cilindro e o aumento do atraso de ignição foram dominantes em reduzir a pressão máxima no cilindro na carga de $10 \mathrm{~kW}$ para os modos IB7E15 (29,5 bar), IB7E20 (29,4 bar), IB7E25 (29,4 bar) e IB7E30 (28,4 bar) (Fig. 2). Os combustíveis IB7E5 e IB7E10 apresentaram os maiores picos de pressão, com valores de 30,4 bar e 29,9 bar, enquanto o B7E0 apresentou 29,7 bar. A menor diferença entre os atrasos de ignição (Fig. 4) e a maior quantidade de combustível queimada na fase pré-misturada da combustão em relação ao óleo diesel padrão causaram o aumento na pressão máxima.

As Figs. 5 e 6 mostram a pressão no interior do cilindro e a taxa líquida de liberação de calor, respectivamente, para a carga de $37,5 \mathrm{~kW}$. Para a carga máxima o motor apresentou instabilidade ao operar com o combustível B7E15. A análise da curva de pressão coletada durante esse ensaio mostrou níveis de pressão abaixo dos apresentados para os outros combustíveis e maior atraso de ignição, $26,8^{\circ} \mathrm{CA}$, enquanto, para as outras misturas, o atraso foi de $21,9^{\circ} \mathrm{CA}, 24,0^{\circ} \mathrm{CA}$ e $24,3^{\circ} \mathrm{CA}$, para B7E0, B7E5 e B7E10, respectivamente. Park et al. [22] apresentaram resultados semelhantes, com instabilidade do motor operando com misturas de óleo diesel e etanol sem modificações mecânicas. Os autores atribuíram o fenômeno ao aumento do atraso de ignição e conseguiram operar o motor ao atrasar a injeção de combustível.

\section{Figura 5 - Pressão no interior do cilindro em função do combustível para carga de $37,5 \mathrm{~kW}$}

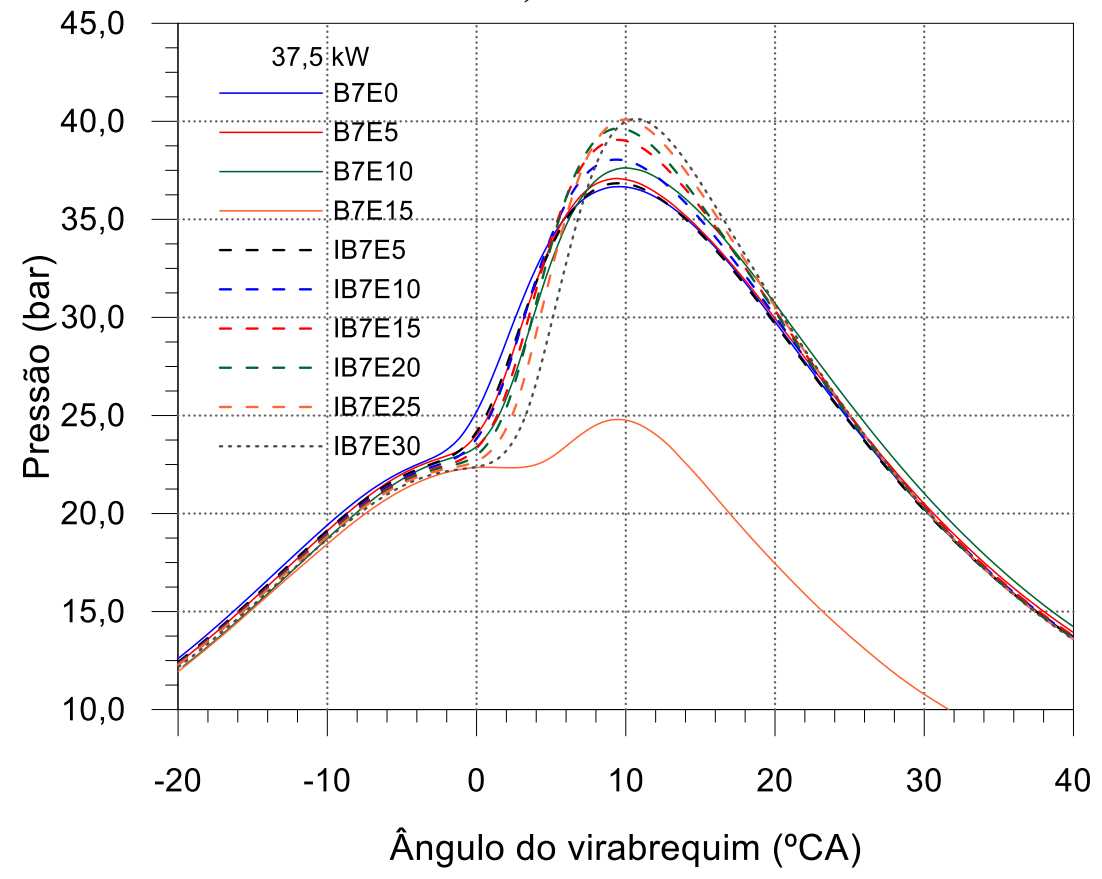

Para a carga de $37,5 \mathrm{~kW}$ o maior pico de pressão nas misturas ocorreu para o combustível B7E10, com 37,6 bar, seguido do B7E5 (37,1 bar) e do óleo diesel padrão B7E0 (36,7 bar) (Fig. 5). Os picos das taxas de liberação de calor foram de 59,7 J/ ${ }^{\circ} \mathrm{CA}$ (B7E10), 58,7 J/ ${ }^{\circ} \mathrm{CA}$ (B7E5) e 49,1 J/ ${ }^{\circ} \mathrm{CA}$ (B7E0) (Fig. 6). Com o aumento da carga aplicada ao motor há a tendência da diminuição do atraso da ignição, já que maiores temperaturas são obtidas [13]. Em cargas altas o efeito do aumento da quantidade de mistura ar/combustível formada durante o atraso de ignição foi dominante para aumentar a taxa de liberação de calor na fase pré-misturada e aumentar o pico de pressão, com aumento da concentração de etanol. Aliado a esse efeito, a redução do atraso de ignição fez com que a combustão ocorresse mais próxima ao PMS. O aumento da taxa líquida de liberação de calor pode aumentar as 
temperaturas locais da estrutura do cilindro, sendo necessária a avaliação da eficiência do sistema de arrefecimento do motor. Os resultados apresentados tiveram comportamento semelhante aos mostrados pelas referências [13, 23, 28, 31].b Em cargas altas o aumento do atraso de ignição causado pela injeção indireta do etanol resulta em maior quantidade de combustível queimada na fase pré-misturada, que, juntamente com a combustão do óleo diesel em uma mistura ar-etanol mais rica, levam ao aumento do pico de pressão e da taxa de liberação de calor.

Figura 6 - Taxa líquida de liberação de calor em função do combustível para a carga de $37,5 \mathrm{~kW}$

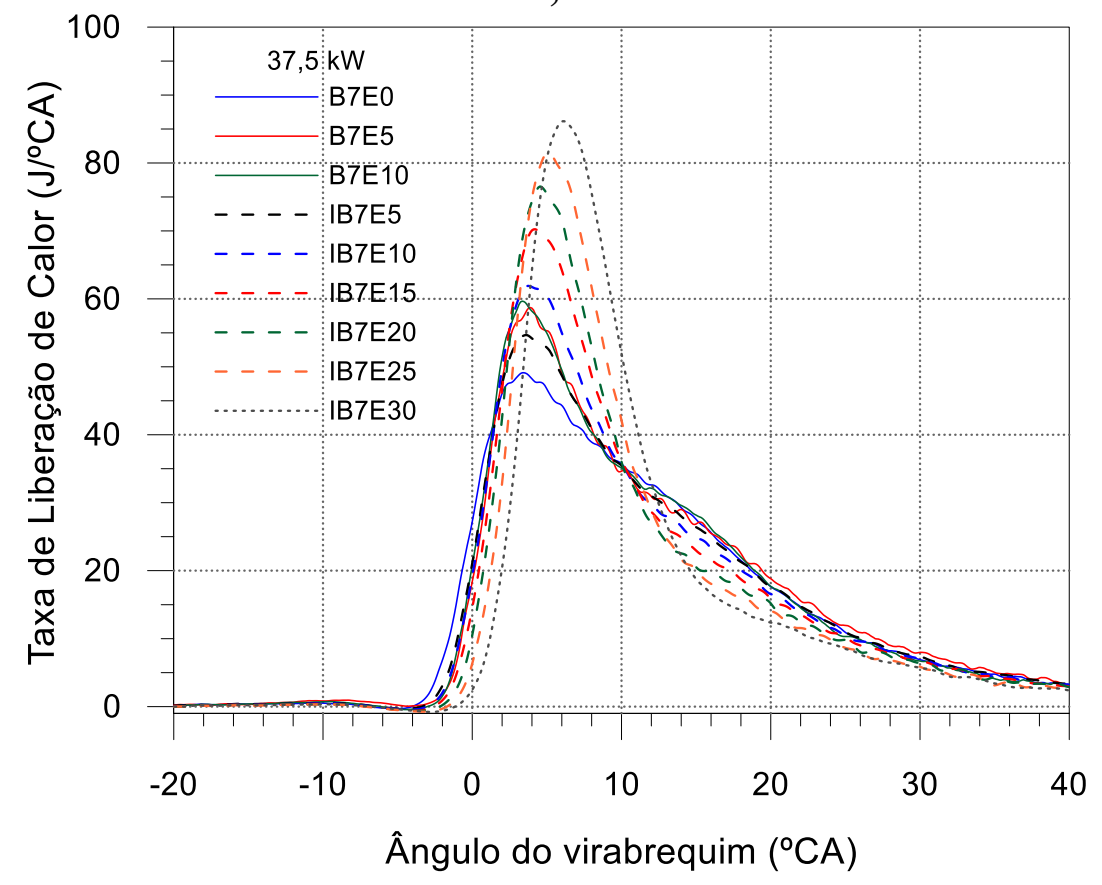

A injeção indireta de etanol a 37,5 kW também causou aumento dos picos de pressão, com magnitudes de 40,1 bar (IB7E30), 40,1 bar (IB7E25), 39,7 bar (IB7E20), 39,1 bar (IB7E15), 38,1 bar (IB7E10), 36,9 bar (IB7E5) e 36,7 bar (B7E0) (Fig. 5). A 37,5 kW a diferença da taxa líquida de liberação de calor entre as diferentes concentrações de etanol foi amplificada (Fig. 6). Com o aumento da concentração de etanol, foi ampliada a magnitude dos picos de taxa de liberação de calor e seu distanciamento do PMS, causado pelo acúmulo de combustível durante o atraso de ignição e pela queima mais rápida do etanol [12]. Os picos encontrados para a carga de $37,5 \mathrm{~kW}$ foram de: $86,1 \mathrm{~J} /{ }^{\circ} \mathrm{CA}$ (IB7E30), 81,6 J/ ${ }^{\circ} \mathrm{CA}$ (IB7E25), 76,5 J/ $/{ }^{\circ} \mathrm{CA}$ (IB7E20), 70,3 J/ ${ }^{\circ} \mathrm{CA}$ (IB7E15), 61,9 J/ ${ }^{\circ} \mathrm{CA}$ (IB7E10), 54,7 J/ ${ }^{\circ} \mathrm{CA}$ (IB7E5) e 49, 1 $\mathrm{J} /{ }^{\circ} \mathrm{CA}$ (B7E0). Diversos autores [5,7,10,12] encontraram resultados semelhantes, com redução da pressão em cargas baixas e aumento em cargas altas, além de aumento do pico da taxa de liberação de calor com o uso de etanol.

Os valores de CA10, CA50 e CA90 foram determinados a partir das curvas de liberação de calor. Para efeito de análise foi considerado que a diferença entre os ângulos CA50 e CA10 (CA50-CA10) corresponde ao período da fase pré-misturada da combustão, a diferença entre CA90 e CA10 a última fase da combustão, e a duração da combustão foi determinada pela diferença entre CA90 e CA10 (CA90-CA10) [39,42]. A Tab. 3 mostra os valores encontrados para todos os combustíveis e, também, o atraso de ignição. 
Tabela 3 - Efeitos do etanol nas características da combustão

\begin{tabular}{|c|c|c|c|c|}
\hline & $\begin{array}{c}\text { CA50-CA10 } \\
\left({ }^{\circ} \mathrm{CA}\right)\end{array}$ & $\begin{array}{c}\text { CA90-CA50 } \\
\left({ }^{\circ} \mathrm{CA}\right)\end{array}$ & $\begin{array}{c}\text { CA90-CA10 } \\
\left({ }^{\circ} \mathrm{CA}\right)\end{array}$ & $\begin{array}{c}\text { Atraso de ignição } \\
\left({ }^{\circ} \mathrm{CA}\right)\end{array}$ \\
\hline \multicolumn{5}{|c|}{ Carga: $10 \mathrm{~kW}$} \\
\hline B7E0 & 4,4 & 12,4 & 16,8 & 24,1 \\
\hline B7E5 & 3,8 & 10,3 & 14,0 & 24,3 \\
\hline B7E10 & 3,9 & 11,2 & 15,1 & 24,6 \\
\hline B7E15 & 3,8 & 9,3 & 13,1 & 26,3 \\
\hline IB7E5 & 4,3 & 12,0 & 16,3 & 24,4 \\
\hline IB7E10 & 4,4 & 12,3 & 16,7 & 24,5 \\
\hline IB7E15 & 4,4 & 12,1 & 16,5 & 24,5 \\
\hline IB7E20 & 4,4 & 12,1 & 16,5 & 24,4 \\
\hline IB7E25 & 4,3 & 11,7 & 16,0 & 24,8 \\
\hline IB7E30 & 4,6 & 12,4 & 17,1 & 25,5 \\
\hline \multicolumn{5}{|c|}{ Carga: 20 kW } \\
\hline B7E0 & 5,0 & 13,8 & 18,8 & 24,3 \\
\hline B7E5 & 4,5 & 12,1 & 16,6 & 24,4 \\
\hline B7E10 & 4,4 & 13,9 & 18,4 & 24,6 \\
\hline B7E15 & 4,0 & 12,3 & 16,3 & 26,5 \\
\hline IB7E5 & 5,0 & 13,2 & 18,1 & 24,4 \\
\hline IB7E10 & 5,0 & 13,4 & 18,4 & 24,8 \\
\hline IB7E15 & 4,9 & 13,3 & 18,1 & 24,7 \\
\hline IB7E20 & 4,8 & 12,6 & 17,4 & 25,2 \\
\hline IB7E25 & 4,6 & 12,9 & 17,5 & 25,1 \\
\hline IB7E30 & 4,9 & 12,6 & 17,5 & 25,4 \\
\hline \multicolumn{5}{|c|}{ Carga: 30 kW } \\
\hline B7E0 & 7,0 & 16,0 & 23,0 & 22,9 \\
\hline B7E5 & 6,7 & 14,7 & 21,4 & 24,0 \\
\hline B7E10 & 6,2 & 14,9 & 21,1 & 24,6 \\
\hline B7E15 & 5,0 & 14,7 & 19,7 & 25,1 \\
\hline IB7E5 & 6,7 & 15,2 & 21,9 & 23,8 \\
\hline IB7E10 & 5,8 & 15,2 & 21,1 & 24,5 \\
\hline IB7E15 & 5,5 & 15,4 & 21,0 & 24,6 \\
\hline IB7E20 & 5,2 & 14,4 & 19,5 & 24,7 \\
\hline IB7E25 & 5,0 & 14,6 & 19,5 & 25,1 \\
\hline IB7E30 & 4,8 & 13,6 & 18,4 & 26,0 \\
\hline \multicolumn{5}{|c|}{ Carga: 37,5 kW } \\
\hline B7E0 & 8,6 & 19,8 & 28,4 & 21,9 \\
\hline B7E5 & 7,9 & 18,3 & 26,1 & 24,0 \\
\hline B7E10 & 7,7 & 17,5 & 25,2 & 24,3 \\
\hline B7E15 & - & - & - & 26,8 \\
\hline IB7E5 & 7,9 & 18,8 & 26,7 & 23,2 \\
\hline IB7E10 & 7,0 & 18,9 & 25,9 & 24,3 \\
\hline IB7E15 & 6,2 & 19,0 & 25,2 & 24,7 \\
\hline IB7E20 & 5,5 & 18,7 & 24,2 & 25,1 \\
\hline IB7E25 & 5,1 & 17,5 & 22,6 & 25,4 \\
\hline IB7E30 & 4,6 & 16,2 & 20,8 & 26,2 \\
\hline
\end{tabular}


Com o aumento da carga do motor há aumento da duração da combustão, devido à maior injeção de combustível e maior duração da formação da mistura ar/combustível [37]. Para todas as cargas, o uso de mistura com etanol causou redução da duração da combustão, explicada pela maior taxa de liberação de calor durante a fase pré-misturada da combustão, devido ao maior atraso de ignição, observada pela redução do período CA50-CA10 com o aumento da concentração de etanol (Tab. 3). Além disso, as misturas de óleo diesel e etanol que possuem maior concentração de etanol reduzem o processo de pirólise e aumentam a oxidação durante a combustão, reduzindo sua duração [31]. A injeção indireta de etanol também aumentou o período de combustão (CA90-CA10) e reduziu a duração da fase prémisturada da combustão (CA50-CA10), sendo mais significativo nas cargas altas e também justificado pelo maior acúmulo de combustível durante o atraso de ignição, causando maior queima de combustível na fase pré-misturada [39]. A queima da mistura ar-etanol é mais rápida em comparação com o óleo diesel, podendo causar o efeito de aumento da eficiência térmica do motor por diminuir o tempo de troca de calor entre o gás e o cilindro [12,18].

Zhu et al. [21] destacam que grandes aumentos nos picos de pressão e de liberação de calor podem causar o fenômeno de detonação no motor, principalmente em altas cargas e altos níveis de atomização de etanol. A taxa de aumento da pressão no interior do cilindro é um parâmetro importante na avaliação da ocorrência de detonação durante a combustão $[3,39,43]$. A Fi. 7 mostra a variação desse parâmetro em função da carga e da concentração de etanol. Pode ser observado que, principalmente em cargas altas, há aumento dessa taxa com aumento da concentração de etanol. Sarjovaara et al. [36] e Curran et al. [43] adotaram o valor de $10 \mathrm{bar} /{ }^{\circ} \mathrm{CA}$ como limite aceitável de taxa de aumento da pressão no interior do cilindro. $\mathrm{O}$ valor máximo encontrado nos experimentos ocorreu para operação na carga de $37,5 \mathrm{~kW}$ com IB7E30, com magnitude de $3,1 \mathrm{bar} /{ }^{\circ} \mathrm{CA}$, situado dentro da faixa aceitável.

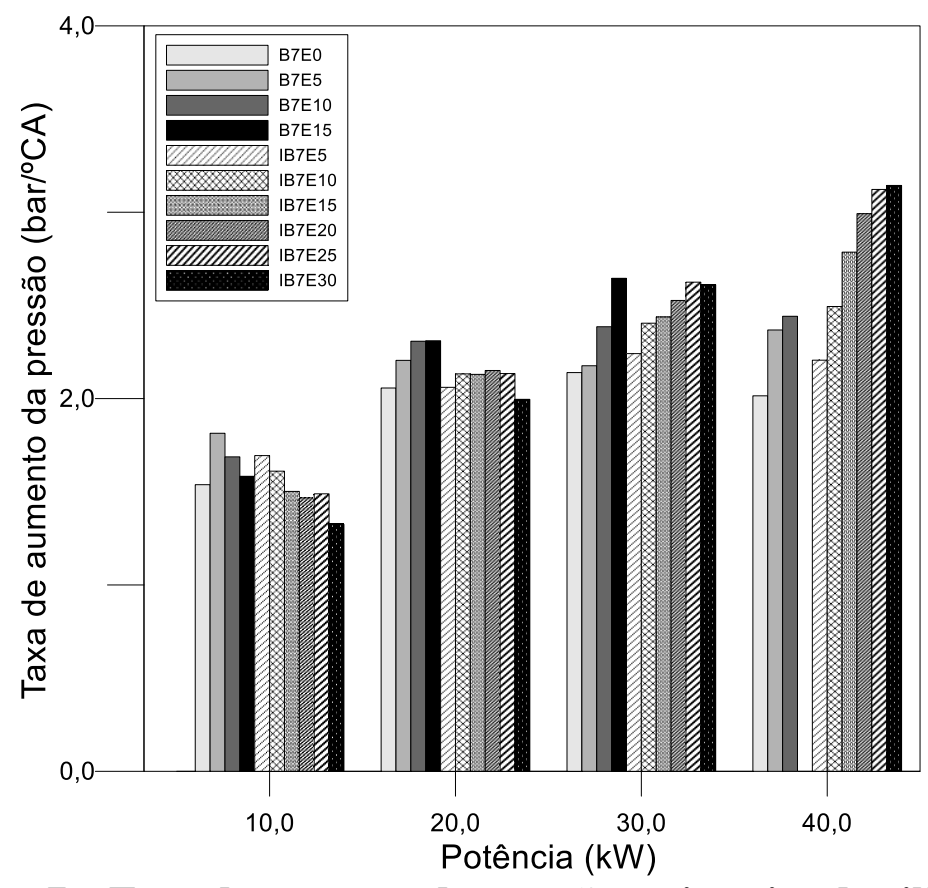

Figura 7 - Taxa de aumento da pressão no interior do cilindro

\section{CONCLUSÕES}

Etanol foi utilizado em um motor diesel através de duas técnicas distintas: injeção direta de misturas de óleo diesel e etanol e injeção indireta de etanol com injeção direta de óleo diesel. 
A concentração de etanol misturado no óleo diesel foi limitada em 15\% pela solubilidade das misturas e pelo comportamento do motor em carga máxima, ocorrendo falha na combustão na operação com $15 \%$ de etanol misturado. O limite de etanol injetado no coletor de admissão foi fixado em $30 \%$ de forma a não danificar o motor. De modo geral houve redução dos picos de pressão em cargas baixas e aumento em cargas altas com o uso do etanol. $\mathrm{O}$ aumento foi mais significativo com injeção indireta de etanol, justificado pela rápida queima desse combustível. Os níveis da taxa de aumento de pressão no interior do cilindro ficaram dentro da faixa aceitável para que não seja caraterizada a detonação, não sendo observados danos ao motor. A adição do etanol aumentou o atraso de ignição, causando menor período da fase pré-misturada da combustão e menor duração da combustão. Em cargas altas foi observada a queima de maior quantidade de combustível durante a fase pré-misturada da combustão. A mistura ar-etanol é queimada mais rapidamente, em comparação com o óleo diesel, podendo aumentar a eficiência térmica do motor por diminuir o tempo de troca de calor entre o gás e o cilindro.

\section{REFERÊNCIAS}

[1] IMRAN, A.; VARMAN, M.; MASJUKI, H.H.; KALAM, M.A. Review on alcohol fumigation on diesel engine performance and reduction of environment concerning emission. Renewable and Sustainable Energy Reviews, v. 26, p. 739-751, 2013.

[2] REITZ, R.D.; DURAISAMY, G. Review of high efficiency and clean reactivity controlled compression ignition (RCCI) combustion in internal combustion engines.

Progress in Energy and Combustion Science, v. 45, p. 12-71, 2015.

[3] PEDROZO, V.B.; MAY, I.; NORA, M.D.; CAIRNS, A.; ZHAO, H. Experiments

analysis of ethanol dual-fuel combustion in a heavy-duty diesel engine: An optimization at low load. Applied Energy, v. 165, p. 166-182, 2016.

[4] SONG, JH; CHEENKACHORN, K.; WANG, J. G.; PEREZ, J.; BOEHMAN, A.

Effect of oxygenated fuel on combustion and emissions in a light-duty turbo diesel engine.

Energy Fuel, v. 16, p. 294-301, 2002.

[5] KOWALEWICZ A. Eco-diesel engine fuelled with rapeseed oil methyl ester and ethanol Part 3: Combustion processes. Transportation Science \& Technology, v. 21, p. 715-723, 2006.

[6] WANG, LJ; SONG, RZ; ZOU, HB; LIU SH; ZHOU, LB. Study on combustion characteristics of a methanol-diesel dual-fuel compression ignition engine. Journal of Automobile Engineering, v. 222, p. 619-627, 2008.

[7] ZHANG, Z.H.; CHEUNG, C.S.; YAO, C.D. Influence of fumigation methanol on the combustion and particulate emissions of a diesel engine. Fuel, v. 111, p. 442-448, 2013.

[8] HANSEN, Alan C.; ZHANG, Qin; LYNE, Peter W. L. Ethanol-diesel fuel blends - a review. Bioresource Technology, v. 96, p. 277-285, 2005.

[9] SURAWSKI, N.C.; RISTOVSKI, Z.D., BROWN, R.J.; SITU, R. Gaseous and particle emissions from an ethanol fumigated compression ignition engine. Energy Conversion and Management, v. 54, p. 145-151, 2012.

[10] ZHU, L.; CHEUNG, C.S.; ZHANF, W.G.; HUANG, Zhen. Emissions characteristics of a diesel engine operating on biodiesel and biodiesel blended with ethanol and methanol.

Science of the Total Environment, v. 408, n. 4, p. 941-921, 2010.

[11] BRITO JR., R.F.; MARTINS, C.A. Experimental analysis of a diesel engine operating in Diesel-Ethanol Dual-Fuel mode. Fuel, v. 134, p. 140-150, 2014.

[12] TSANG, K.S.; ZHANG Z.H.; CHEUNG, C.S., CHAN, T.L. Reducing Emissions of a Diesel Engine Using Fumigation Ethanol and a Diesel Oxidation Catalyst. Energy Fuel, v. 24, p. 6156-6165, 2010. 
[13] HULWAN, D.B.; JOSHI, S.V. Performance, emission and combustion characteristic of a multicylinder DI diesel engine running on diesel-ethanol-biodiesel blends of high ethanol content. Applied Energy. v. 88, n. 12, p. 5042-5055, 2011.

[14] LI, X.; QIAO, X., ZHANG, L., FANG, J.; HUANG, Z.; XIA, H. Combustion and emission characteristics of a two stroke diesel engine opeating on alcohol. Renewable Energy, v. 30, p. 2075-2084, 2005.

[15] SAHIN, Z.; DURGUN, O. Theoretical investigation of effects of light fuel fumigation on diesel engine performance and emissions. Energy Conversion and Management, v. 48, p. 1952-1964, 2007.

[16] BALLI, O.; HAYDAR, A.; ARIF, H. Thermodynamic and Thermoeconomic analysis of a trigeneration (TRIGEN) system with a gas-diesel engine: Part II An application.

Energy Conversion and Management, v. 51, p. 2260-2271, 2010.

[17] BORETTI, A. Advantages of converting Diesel engines to run as dual fuel ethanolDiesel. Applied Thermal Engineering, v. 47, p. 1-9, 2012.

[18] ABU-QUDAIS, M.; HADDAD, O.; QUDAISAT, M. The effect of alcohol fumigation on diesel engine performance and emissions. Energy Conversion \& Management, v. 41, p. 389-399, 2000.

[19] SURAWSKI, N.C.; MILJEVIC, B.; ROBERTS, B.A.; MODINI, R.L.; SITU, R.; BROWN, R.J.; BOTTLE, S.E.; RISTOVSKI, Z.D. Particle Emissions, Volatility, and toxity from an ethanol fumigated compression ignition engine. Environmental Science \& Technology, v. 44, n. 1, 2010.

[20] SAHIN, Z.; DURGUN, O.; KURT, M. Experimental investigation of improving diesel combustion and engine performance by ethanol fumigation-heat release and flammability analysis. Energy Conversion and Management, v. 89, p. 175-187, 2015. [21] HUANG, J.; WANG, Y.; LI, S.; ROSKILLY, A.P.; YU, H.; LI, H. Experimental investigation on the performance and emissions of a diesel engine fuelled with ethanoldiesel blends. Applied Engineering, v. 29, p. 2484-2490, 2009.

[21] ZHU, L.; CHEUNG, C. S.; ZHANG, W. G.; FANG, J.H.; HUANG, Z. Effects of ethanol-biodiesel blends and diesel oxidation catalyst (DOC) on particulate and unregulated emissions. Fuel, v. 113, p. 690-696, 2013.

[22] PARK, S. H.; YOUN, L. M., LEE, C.S. Influence of ethanol blends on the combustion performance and exhaust emission characteristics on a four-cylinder diesel engine at various engine loads and injection timings. Fuel, v. 90, p.748-755, 2011.

[23] FANG, Q.; FANG, J.; ZHUANG, J.; ZHEN, H. Effects of ethanol-diesel-biodiesel blends on combustion emissions in premixed low temperature combustion. Applied Thermal Engineering, v. 54, p. 541-548, 2013.

[24] YILMAZ, N.; VIGIL, F. M.; DONALDSON, A. B.; DARABSEH, T. Investigation of $\mathrm{CI}$ engine emissions in biodiesel-ethanol-diesel blends as a function of ethanol concentration. Fuel, v. 115, p. 790-793, 2014.

[25] KIM, H.; CHOI, B. Effect of ethanol-diesel blends fuels on emission and particle size distribution in a common-rail direct injection diesel engine with warm-up catalytic converter. Renewable Energy, v. 33, p. 2222-2228, 2008.

[26] PIDOL, L.; LECOINTE, B.; STARCK, L.; JEULAND, N. Ethanol-biodiesel-Diesel fuel blends: Performances and emissions in conventional Diesel and advanced Low Temperature Combustions. Fuel, v. 93, p. 329-338, 2012.

[27] ARMAS, O.; GARCÍA-CONTRERAS, R.; RAMOS, Á. Pollutant emissions from New European Driving Cycle with ethanol and butanol diesel blends. Fuel Processing Technology, v. 122, p. 64-71, 2014. 
[28] MOHAMMADI, A.; ISHIYAMA, T.; KAKUTA, T.; KEE, S.-S. Fuel Injection Strategy for Clean Diesel Engine Using Ethanol Blended Diesel Fuel. SAE Technical Papers Series, v. 2005-01-1725, 2005.

[29] SHI, X.; PANG, X.; MU, Y.; HE, H.; SHUAI, S.; WANG, J.; CHEN, H.; LI, R. Emission reduction potential using ethanol-biodiesel-diesel fuel blend on a heavy-duty diesel engine. Atmospheric Environment, v. 40, p. 2567-2574, 2006.

[30] SAYIN, C.; USLU, K.; CANAKCI, M. Influence of injection timing on the exhaust emissions of a dual-fuel CI engine. Renewable Energy, v. 33, p. 1314-1323, 2008.

[31] ZHU, L.; CHEUNG, C. S.; ZHANG, W. G. Combustion, performance and emission characteristics of a DI diesel engine fueled with ethanol-biodiesel blends. Fuel, v. 90, p. 1743-1750, 2011.

[32] OLIVEIRA, A.; MORAIS, A. M.; VALENTE, O. S.; SODRÉ, J. R. Combustion characteristics, performance and emissions from a diesel power generator fuelled by B7ethanol blends. Fuel Processing Technology, v. 139, p. 67-72, 2015.

[33] BODISCO, T.; BROWN, R. J. Inter-cycle variability of in-cylinder pressure parameters in an ethanol fumigated common rail diesel engine. Energy, v. 52, p. 55-65, 2013.

[34] TUTAK, W. Bioethanol E85 as a fuel for dual fuel diesel engine. Energy Conversion and Management, v. 86, p. 39-48, 2014.

[35] REZENDE, H.; FURQUIM, R.; ODLEVAK, E.; CRUZ, E.; ELIZARDO, R.; SALLES, E.; MOLGORI, S. Ethanol Diesel Truck Engine. SAE Technical Papers Series, 2011-360319 E, 2011.

[36] SARJOVAARA, T.; ALANTIE, J., LARMI, M. Ethanol dual-fuel combustion concept on heavy duty engine. Energy, 63, p. 76-85, 2013.

[37] HANSDAH, D.; MURUGAN, S. Bioethanol fumigation in a DI diesel engine. Fuel, v. 130, p. 324-333, 2014.

[38] SARJOVAARA, T.; LARMI, M. Dual Fuel Combustion with an E85 ethanol/gasoline blend. Fuel, v. 139, p. 704-714, 2015.

[39] JAMUWA, D. K.; SHARMA, D.; SONI, S. L. Experimental investigation of performance, exhaust emission and combustion parameters of stationary compression ignition engine using etanol fumigation in dual fuel mode. Energy Conversion and Management, v. 115, p. 221-231, 2016.

[40] KATRASNIK, T., TRENC, F., OPRESNIK, S.R., A New Criterion to Determine the Start of Combustion in Diesel Engines, Journal of Engineering for Gas and Turbines, v. 128, p. 928-933, 2006.

[41] HEYWOOD, J. B. Internal combustion engine fundamentals. New York: McGrawHill, xxxiv, 930p, 1988.

[42] PARK, S. H.; CHA, J.; LEE, C. S. Impact of biodiesel in bioethanol blended diesel on the engine performance and emissions characteristics in compression ignition engine.

Applied Energy, v. 99, p. 334-343, 2012.

[43] CURRAN, S. J; HANSON, R. M; WAGNER, R. M. Reactivity controlled compression combustion on a multi-cylinder light-duty diesel engine. International

Journal of Engine Research, v. 13, p. 216-225, 2012. 